\title{
Research on the Practical Teaching System Construction of Creative and Entrepreneurship Education in Colleges
}

\author{
Wei Gao ${ }^{1, a}$, Haiying Zhang ${ }^{1, b^{*}}$ and Xiaojie Lv ${ }^{1, c}$ \\ ${ }^{1}$ Qingdao Binhai University, Qingdao, China, 266555 \\ a1533150757@qq.com, b64029205@qq.com, 497507273@qq.com \\ *The corresponding author
}

Keywords: Colleges; Creative and entrepreneurship; Practical teaching system construction; Path

\begin{abstract}
Entering 20th century, China started to carry out creative and entrepreneurship education and its practical teaching system construction is related to teacher's knowledge improvement, and the enthusiasm for college students to carry out creative activities. What's more, it also depends on the perfection of capital and platform education institutions have done. Along with the development of times, we should start to solve the current problems and reflect to get experience. What's more, colleges should strengthen the construction of creative and entrepreneurship education and take 'having stores in front and factories behind' as an example to build 'having stores in front and colleges behind' to further discuss its implementation.
\end{abstract}

\section{Introduction}

On 2015 May, General Office of the State Council issued 'implementation suggestions on deepening the creative and entrepreneurship education reform', pointing out highlighted problems that the single teaching system is separated from the practice and the creative and entrepreneurship education remains to be improved, which ask new demand for college creative and entrepreneurship education. At present, college education system focuses more on theory, and shortages brought by this can be fixed. However, whether we can improve the shortage or not depends on the efforts to perfect the current teaching system and combine it with practice to make it better. Based on this, we can construct a creative and entrepreneurship education system to guarantee the development. In addition, how to build a demonstrative, popular and operational system for college creative and entrepreneurship education is what the paper wants to discuss and study.

\section{The Significance of Carrying out Creative and Entrepreneurship Education}

The core for colleges to carry out creative and entrepreneurship education is to combine it with professional talents cultivation so as to improve students' innovative spirit and promote the dissemination of innovative spirit. In addition, creative and entrepreneurship has powerful practicality and subjectivity. Students, as the master they can get experience during the entrepreneurship based on fully playing their advantages. The combination between project adventure and classroom theory teaching (or case explanation) can help to improve the practicality and subjectivity development. Therefore, the construction of a sound and perfect college creative and entrepreneurship practice is the base to realize the creative and entrepreneurship education. The meaning to construct practical teaching system is to cultivate good faculties. Faculties are valuable and excellent resources of colleges and colleges should encourage teachers to build their own team or come to the first production line to learn. What's more, colleges can also recruit enterprises to give lectures in school. To conclude, a multi-layer and three dimensional teaching mode should be built to ignite the enthusiasm of students. In addition, entrepreneurs should also share their experience with students to guide them.

Training platform: an entrepreneurship with a good atmosphere is another advantage while the platform as well as opportunities can attract more students to participate in. Colleges can cooperate 
with enterprises and relevant departments to provide technical and theoretical support based on the system of 'nursery- incubator- accelerator' so as to encourage them to carry out entrepreneurship.

The integration of theory and platform can encourage students to take the initiative to carry out entrepreneurship so as to provide more opportunities and platform, which will be helpful to let students get new ideas. The mode of taking practice as the dominance and theory as supplement does not mean to ignore the importance of creative and entrepreneurship education but to encourage students to participate more in practice. Before entrepreneurship, students get the access to know more about requirements, which can help them deepen the impression. Based on this, we can highlight the meaning of creative and entrepreneurship which can provide new ideas for students at the same time getting experience.

\section{The Present Situation of the Teaching System of Creative and Entrepreneurship Education in Colleges}

In 1997, the Ministry of Education mentioned about encouraging teachers and students to carry out entrepreneurship in Action Scheme for Invigorating Education Towards the 21st Century and colleges started to provide entrepreneurship classes. In 2000, college entrepreneurship education carried out pilot project. Tsinghua University as sell as Peking University started to make entrepreneurship conception and provide entrepreneurship class and practical entrepreneurship education as well as comprehensive entrepreneurship education. In 2012, the Ministry of Education launched Basic requirements for common college's creative and entrepreneurship (trial implementation) to formally started entrepreneurship education. In 2015, colleges all over the nation had built a perfect entrepreneurship education system and there are creative and entrepreneurship class as well as entrepreneurship schools. However, it is still in the first stage and there are problems left showing as follows:

It is not closely related to the reality, especially the professional major. Entrepreneurship is a part of business so it is not closely related to the profession in engineering school as well as comprehensive schools. Most of the classes are related to management so if colleges cannot relate it to society, it will affect the enthusiasm and promotion depth. In addition, it is also not related to the policy. The government has launched a series of creative and entrepreneurship policies. For example, Beijing Municipal Bureau of Finance and Beijing Education Council cooperated to lunch Employment business management methods for college students in Beijing and will give 200 thousand RMB to excellent entrepreneurship groups. However, this policy is popularized in first-tier cities and the government did not provide powerful policies to support it. Colleges, as important roles should increase their awareness of the policies and provide more policy and technical support. Based on the condition, students lack bold and challenging spirit.

The government can provide the following policies for students: 1) entrepreneurship tax preference; 2) secured loan and interest subsidies; 3) free administrative institutional fees; 4) training assistance; 5) free entrepreneurship service; 6) cancel the registration limit; 7) innovative talents cultivation; 8) provide creative and entrepreneurship course; 9)strengthen creative and entrepreneurship practice; 10) change teaching system; 11) perfect student management rules; 12) career guidance for undergraduates. Judging from the national policy, we can see that we should combine creative and entrepreneurship education to practical teaching system. What's more, the government should provide support in terms of policies, capital and technology. Furthermore, enterprises should also encourage students to take the initiative to carry out entrepreneurship and provide free training opportunities to provide a good platform for students. Colleges, as parts of creative and entrepreneurship education, they should know how to combine theory to practice and embrace new challenges.

\section{Solutions for Colleges to Carry out Practical Teaching}

Construct campus entrepreneurship platform. The practice base for creative and entrepreneurship is the main platform to help students take the initiative to carry out entrepreneurship, improves 
creative abilities, strengthen innovative spirit, and cultivate students' enthusiasm. Starting from campus, we should expand to enterprises and societies to help students independently carry out entrepreneurship and build a mode of 'having stores in front and schools behind'. In addition, we should share campus resources. The advantage for colleges to carry out practice is that colleges are equipped with lots of experimental facilities as well as labs. Based on this, we should satisfy the requirements of students to carry out entrepreneurship projects and build a wholesome mechanism. According to scale, function and time, we should also timely adjust and fix to on the one hand reduce the cost and on the other hand improve the efficiency. Colleges are equipped with internal market. We should start from colleges, we should carry out statistics to know more information and get a initial understanding on the market as well as demands. Overall, the creative and entrepreneurship base is the transition from colleges to stores, which can be beckoned as a basic platform for cultivating students' abilities. Furthermore, we should also strengthen the basic infrastructure of entrepreneurship schools. Frankly, lots of colleges have pioneer park or technology park, but how can these parks work well is a question. Entrepreneurship park should be built by the government and colleges together. While carrying out entrepreneurship practice, incubation, and service, students can carry out entrepreneurship experiment based on their innovative ideas. Taking engineering schools as an example, relevant entrepreneurship facilities should combine with engineering courses because the entrepreneurship related to majors should be the best. On the one hand, colleges should carry out overall arrangements and the setting should be proper. Concerning the creative and entrepreneurship education form we should carry out diversified development. Furthermore, special lectures, experts teaching and typical case introduction as well as enterprise visit can help to create students' creative and entrepreneurship ideas. Real entrepreneurship is beneficial to let students know their shortcomings and make up for idea deviation. In addition, we have to deepen the cooperation between colleges and enterprises to strengthen students' practical consciousness. Going out of the ivory tower to be exposed to the society is a necessary process to carry out entrepreneurship. By visiting enterprises and experiencing the production process will be meaningful to help students comprehensively understand entrepreneurship, which will be helpful to develop students' all-round abilities. It actually helps to develop their professional ethnics and responsibilities. By the way, the cooperation between colleges and enterprises is not only beneficial to student entrepreneurship as well as teachers' practical ability and keep talents for enterprises. The full adoption of this platform is a strong impetus for campus creative and entrepreneurship education.

Create special creative and entrepreneurship courses. Renmin University of China published Certain Opinions on Strengthening Creative and Entrepreneurship as well as Practical Work along with deepened reform, which clears the goal of education to cultivate talents adapted to the society and make education link to the society. What's more, the idea of teaching students according to their aptitude suggests us to construct courses with their own features. The specialty of the course can be adapted to different subjects and majors. In addition, the combination between actual educations to innovative ideas should be highlighted to construct a new mode. That is to say, we should focus on both professional knowledge and enterprise ideas to help students behave well.

Simplify the structure of entrepreneurship education organization. The current creative and entrepreneurship education structure is single and fixed. To build a multi-dimensional, wide-extensive organization is a must to develop creative and entrepreneurship. According to the principle of 'having stores in front and schools behind', colleges should focus on the cooperation with markets. Colleges should also strengthen the direct cooperation between students and entrepreneurship platform; simplify the steps so as to quickly make entrepreneurship on path. If colleges can clearly understand talents, students can also quickly adapt to entrepreneurship pace.

Carry out entrepreneurship during practice, evaluate in entrepreneurship, and establish evaluation system. The normal operation of an enterprise cannot be separated from the management and decision system. A famous theory of management is called SMART rule and the formulation of evaluation standards can help to effectively facilitate the development of entrepreneurs and improve themselves, in addition, creative and entrepreneurship education cannot stay on the spiritual level. 
To build a perfect evaluation system can help to guide students and is more practical. What's more, the formulation of evaluation system can strengthen the practical and applied abilities. To fully play the advantage of assessment we have to focus on both the procedure and results. Furthermore, bi-directional assessment will provide more communication opportunities for students and teachers which can also help to build a whole set to cultivate creative and entrepreneurship talents.

\section{Conclusions}

Nowadays, China has entered now normal economy condition, and more students will choose entrepreneurship. What's more, colleges are paying more and more attention to creative and entrepreneurship while practice is the only standard to test truth. If college's creative and entrepreneurship want to reach the teaching objects and effect, colleges should strengthen the combination with reality so as to let students participate in practice wit the application of theory. The establishment and development of college creative and entrepreneurship practical teaching system is being improved nowadays, and colleges will pay more attention to encourage to students carry out entrepreneurship and practice.

\section{References}

[1] Jiang Deqin. Discuss on the quality evaluation system construction for college creative and entrepreneurship. 2015.

[2] Shu Tie, Yu Wenhua, Zhou Lingyu, Xu Jianying. Discuss on the practical system construction of creative and entrepreneurship education [J]. 2011. (10).9.

[3] Zhou Guijin. Policies to construct creative and entrepreneurship education system for higher vocational schools [J]. Jiangsu Higher Education, 2011.

[4] $\mathrm{Hu}$ Tao, Shen Li. Enlightenment of creative and entrepreneurship education of foreign countries to colleges in China [J]. Chinese college education, 2013.

[5] Hua Chunge, Wang Jingjing. Brief talk on college creative and entrepreneurship education reform- reflection arisen from difficult employment of students [J]. Journal of Shanxi Finance and Economics University, 2011.

[6] State Council's implementation suggestions to strengthen college creative and entrepreneurship education reform.

[7] Opinions on promoting college creative and entrepreneurship education.

[8] Xiao Xiaoshu. Application of creative and entrepreneurship education in entrepreneurship and practical teaching $[\mathrm{J}]$. China Modern Educational Equipment.

[9] Lin Liping. Innovational and enterprising talents cultivation system construction [J] . China Youth Study, 2009.

[10]Wang Fangguo. Study on creative and entrepreneurship ability cultivation based on practical teaching reform $[\mathrm{J}]$. Journal of Higher Education, 2015. 